\title{
OPTIMASI PORTOFOLIO PADA SAHAM PEFINDO 25 DENGAN MENGGUNAKAN MODEL MARKOWITZ (STUDI KASUS DI BURSA EFEK INDONESIA)
}

\author{
Made Pratiwi Dewi \\ Faculty of Economic and Bussiness, Universitas Warmadewa, Denpasar, Bali-Indonesia \\ pratiwidewi 88@yahoo.com
}

\begin{abstract}
How to cite (in APA style):
Dewi, Made, Pratiwi.Optimasi Portofolio Pada Saham PEFINDO 25 Dengan Menggunakan Model MARKOWITZ (Studi Kasus Di Bursa Efek Indonesia). Warmadewa Management and Business Joural, 3(1) pp.32-42
\end{abstract}

\begin{abstract}
Fund investment activities in the capital market required expertise to minimize the investment risk. One way was to form a portfolio. Markowitz model helped investors determined the stocks which was the member of the optimal portfolio. Minimization of risk and maximization of return became the urgent thing, and the value of the return expectation became the basis of calculation. This research used non probability sampling to select Pefindo 25 indeks stocks at BEI as a population and sample. Results showed from 25 sample that only 6 (six) stocks were included in the optimal portfolio, which was Adi Sara Armada Tbk (ASSA), Wilmar Cahaya Indonesia Tbk (CEKA), Elnusa Tbk (ELSA), Erajaya Swasembada Tbk (ERAA), Champion Pacific Indonesia Tbk (IGAR), dan Vale Indonesia Tbk (INCO). The optimal investment portfolio provided total expected return portfolio was 15.592 percent and a risk of deviation / variance portfolio was 0.108 percent.
\end{abstract}

Keyword: investment, optimal portfolio, Markowitz model

\begin{abstract}
Abstrak
Kegiatan investasi dana di pasar modal membutuhkan keahlian untuk meminimalkan risiko investasi. Salah satunya adalah dengan membentuk portofolio. Model Markowitz membantu investor menentukan saham-saham yang menjadi anggota portofolio optimal. Minimisasi risiko dan maksimalisasi return menjadi hal yang mendesak, dan nilai ekspektasi return menjadi dasar perhitungan. Penelitian ini menggunakan non probability sampling untuk memilih saham indeks Pefindo 25 di BEI sebagai populasi dan sampel. Hasil penelitian menunjukkan dari 25 sampel hanya 6 (enam) saham yang masuk dalam portofolio optimal yaitu Adi Sara Armada Tbk (ASSA), Wilmar Cahaya Indonesia Tbk (CEKA), Elnusa Tbk (ELSA), Erajaya Swasembada Tbk (ERAA), Champion Pacific Indonesia Tbk (IGAR), dan Vale Indonesia Tbk (INCO). Portofolio investasi optimal dengan catatan total ekspektasi return portofolio sebesar 15,592 persen dan risiko penyimpangan / varians portofolio sebesar 0,108 persen.
\end{abstract}

Kata kunci: investasi, portofolio optimal, model Markowitz

\section{PENDAHULUAN}

Iklim investasi dalam negeri mengalami perubahan ke arah yang positif. Kembali diraihnya posisi investment grade dan ketahanan Indonesia dalam 
menghadapi krisis yang melanda Eropa dan Amerika menjadikan Indonesia sebagai salah satu destinasi investasi yang menarik. Investasi dapat dilakukan, salah satunya dengan membentuk portofolio. Investor yang berinvestasi dalam bentuk portofolio perlu melakukan analisis terhadap peluang return dan risiko yang akan dihadapi. Return (tingkat pengembalian) dan risiko berhubungan searah, yang artinya besar return akan sesuai dengan tingkat risikonya.

Model penentuan portofolio yang menekankan pada hubungan return dan risiko investasinya adalah model Markowitz. Model ini dapat mengatasi kelemahan dari diversifikasi random. Anggapan bahwa penambahan jumlah saham dalam satu portofolio secara terus menerus akan memberikan manfaat yang semakin besar, berbeda dengan model Markowitz. Model ini meyakini bahwa penambahan saham secara terus menerus pada satu portofolio, pada suatu titik tertentu akan semakin mengurangi manfaat diversifikasi dan justru akan memperbesar tingkat risiko (Tandelilin, 2010:116). Penentuan portofolio efisien merupakan hal terpenting yang harus diperhatikan dalam menentukan portofolio optimal. Model Markowitz menunjukkan bahwa varians dari return portofolio pada sekuritas finansial tidak hanya bergantung pada seberapa berisikonya aset individual dalam portofolio tetapi lebih kepada hubungan risiko tersebut terhadap sekuritasnya (Suqaier \& Ziyud, 2011).

Semakin berkembangnya zaman di era modern ini banyak saham-saham yang terdaftar di Bursa Efek Indonesia yang membuat bingung para investor untuk memilih saham apa yang akan diinvestasikannya di masa akan datang. Oleh karena itu BEI mengeluarkan jenis-jenis saham berdasarkan kriteria tertentu yang nantinya akan dipilih oleh investor seperti Indeks Harga Saham Gabungan, Indeks Sektoral, Indeks LQ45, Jakarta Islamic Index (JII), Indeks Kompas100, Indeks Bisnis-27, Indeks Pefindo 25, Indeks Sri-Kehati, Indeks Papan Utama Dan Papan Pengembangan, serta Indeks Individaual (Buku Panduan IHS BEI : 2010). Penelitian ini menggunakan Indeks Pefindo 25 yang artinya PT Bursa Efek Indonesia bekerja sama dengan lembaga rating Pefindo, meluncurkan indeks harga saham yang diberi nama Indeks Pefindo 25. Indeks ini dimaksudkan untuk memberikan tambahan pedoman investasi bagi pemodal yaitu dengan membuat suatu benchmark indeks baru yang secara khusus membuat kinerja saham emiten kecil dan menengah (Small Medium Enterprises / SME) melalui kriteria dan metodologi yang konsisten.

Beberapa pokok permasalahan yang dapat dirumuskan, yaitu saham-saham perusahaan indeks Pefindo 25 manakah yang termasuk dalam kombinasi portofolio optimal dengan menggunakan model Markowitz, seberapa besar proporsi dana yang harus diinvestasikan pada masing-masing saham perusahaan dan tingkat return portofolio yang diharapkan serta risiko dari portofolio optimal tersebut. Penelitian ini bertujuan mengetahui saham-saham yang termasuk dalam kombinasi portofolio optimal, besar alokasi dana, tingkat return, serta risiko dari portofolio optimal yang terbentuk.

\section{TELAAH LITERATUR DAN KAJIAN PUSTAKA}

\section{Investasi}

Investasi Tujuan berinvestasi yaitu untuk mendapatkan kehidupan yang lebih layak di masa depan. Djokopranoto (2011), mendefinisikan investasi sebagai suatu kesepakatan pada pasar dana dari satu atau lebih asset yang akan diperoleh untuk periode yang akan datang. Reilly dan Brown (2003) menyatakan bahwa investasi adalah komitmen atas sejumlah dana pada masa sekarang atau beberapa periode waktu dengan maksud untuk mendapatkan pembayaran dimasa depan yang akan memuaskan para investor. Menurut Bodie et al. (2006), an investment is the current commitment of money or other resorces in the expectation of 
reaping future benefits. Dari beberapa definisi tersebut dapat disimpulkan bahwa investasi adalah kegiatan yang dilangsungkan dengan memanfaatkan aset berwujud maupun tidak berwujud pada masa sekarang ini, dengan tujuan untuk menghasilkan keuntungan di masa yang akan datang.

\section{Hubungan Risk dengan Expected Return}

Hubungan tingkat resiko dan return ekspektasi yang diharapkan merupakan hubungan yang bersifat positif. Artinya semakin besar risiko suatu sekuritas, semakin besar pula return yang diharapkan, (high yield means high risk), demikian sebaliknya (Rose, 2012). Hal tersebut dapat dilihat pada Gambar 1.

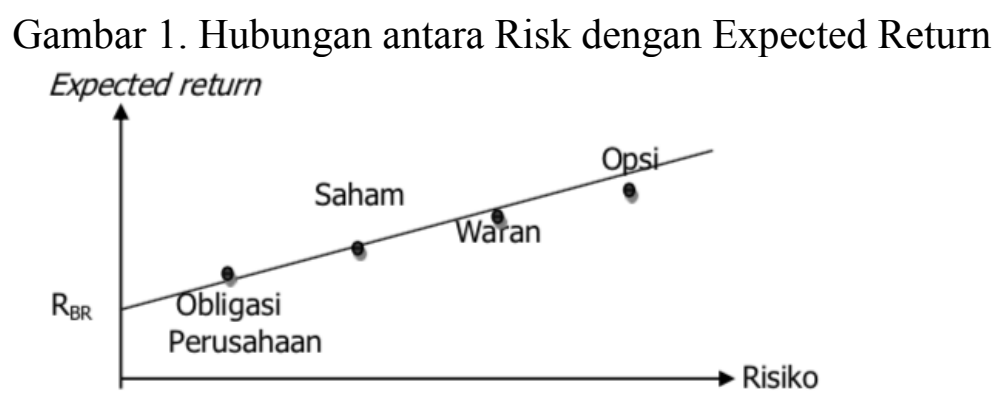

Sumber: Jogiyanto, 1998

Gambar 1 Hubungan Antara Tingkat Risiko dan Return yang diharapkan (Jogiyanto, 1998) Gambar diatas menunjukan adanya hubungan positif antara return ekspektasi dengan risiko. Garis vertikal dalam gambar menunjukan besarnya tingkat hasil yang diharapkan yang layak, sedangkan garis horizontal memperlihatkan risiko yang ditanggung investor. Titik RBR pada gambar menunjukan return bebas risiko (risk-free rate). RBR pada gambar di atas menunjukan satu pilihan investasi yang menawarkan return sebesar RBR dengan risiko sebesar nol (0).

\section{Portofolio}

Teori portofolio merupakan teori modern mengenai pengambilan keputusan dalam situasi ketidakpastian (Weston dan Copeland, 1997). Makowitz (1952) mendefinisikan bahwa teori portofolio berkaitan dengan estimasi investor tehadap ekspektasi risiko dan return, yang diukur secara statistik untuk membuat portofolio investasinya. Markowitz menjabarkan cara mengkombinasikan aset ke dalam diversifikasi portofolio yang efisien. Dalam portofolio ini, risiko dapat dikurangi dengan menambah jumlah jenis aset ke dalam portofolio dan tingkat expected return dapat naik jika investasinya terdapat perbedaan pergerakan harga dari aset-aset yang dikombinasi tersebut. Menurut Koch et al. (2008), portofolio merupakan istilah yang digunakan untuk menjelaskan sekumpulan aset. Portofolio dapat mencakup saham, obligasi, saham reksadana, minyak, emas, kartu bisbol, karya seni atau benda lainnya yang memiliki nilai.

\section{Indeks Pefindo 25}

Pefindo 25 adalah indeks harga saham dengan anggota terdiri dari perusahaan kecil dan mengengah (SME) yang diseleksi dengan kriteria tertentu. Pefindo 23 telah diperkenalkan pada tanggal 18 Mei 2009 dan ditelaah setahun 2 kali, yakni pada setiap bulan Januari dan Juli. 


\section{METODE PENELITIAN}

Penelitian ini merupakan penelitian deskriptif yang menggambarkan penentuan model portofolio optimal dengan didasarkan atas fakta-fakta dan data yang ada. Pembentukan portofolio optimal menggunakan model Markowitz dan dilakukan pada saham indeks Pefindo 25 yang terdaftar di Bursa Efek Indonesia periode Januari 2016 Juli 2016. Data diperoleh dari situs resmi Bursa Efek Indonesia, yaitu www.idx.co.id.

Populasi dari penelitian ini yaitu seluruh perusahaan yang terdaftar di Indeks Pefindo 25. Sampel dari penelitian ini menggunakan teknik non probability sampling yaitu menggunakan teknik sensus, dimana semua anggota populasi dijadikan sampel. Oleh karena semua populasi dijadikan sampel maka sampel dalam penelitian ini berjumlah 25 dari 25 saham yang menjadi populasi, seperti yang ditujukan pada Tabel 1.

Tabel 1 Kode Perusahaan dan Closing Price pada Perusahaan Indeks Pefindo 25 yang Terdaftar di Bursa Efek Indonesia Periode Januari - Juli 2016

\begin{tabular}{|c|c|c|c|c|c|c|c|c|}
\hline \multirow{2}{*}{ No } & \multirow{2}{*}{$\begin{array}{c}\text { Kode } \\
\text { Saham }\end{array}$} & \multicolumn{7}{|c|}{ Periode Closing Price } \\
\hline & & $31 / 01 / 2016$ & $29 / 02 / 2016$ & $31 / 03 / 2016$ & $29 / 04 / 2016$ & $31 / 05 / 2016$ & $30 / 06 / 2016$ & $31 / 07 / 2016$ \\
\hline 1 & ACES & 800,00 & 915,00 & 895,00 & 925,00 & 830,00 & 925,00 & 970,00 \\
\hline 2 & ARNA & 484,00 & 565,00 & 625,00 & 600,00 & 580,00 & 610,00 & 580,00 \\
\hline 3 & ASSA & 100,00 & 100,00 & 115,00 & 115,00 & 116,00 & 3,00 & 164,00 \\
\hline 4 & BISI & $1.270,00$ & $1.445,00$ & $1.765,00$ & $1.665,00$ & $1.750,00$ & $1.750,00$ & $1.760,00$ \\
\hline 5 & BUVA & 575,00 & 610,00 & 595,00 & 610,00 & 605,00 & 550,00 & 630,00 \\
\hline 6 & CASS & $1.060,00$ & $1.245,00$ & $1.130,00$ & $1.100,00$ & $1.000,00$ & 975,00 & $1.000,00$ \\
\hline 7 & CEKA & 610,00 & 610,00 & 690,00 & 730,00 & $1.100,00$ & 975,00 & $1.260,00$ \\
\hline 8 & CMNP & 2.21 & $1.770,00$ & $1.825,00$ & $1.765,00$ & $1.765,00$ & $1.715,00$ & $1.720,00$ \\
\hline 9 & CSAP & 378,00 & 410,00 & 00 & 423,00 & 434,00 & 414,00 & 396,00 \\
\hline 10 & CII & 700,00 & 715,00 & 670,00 & 650,00 & 484,00 & 500,00 & 550,00 \\
\hline 11 & EKAD & 399,00 & 414,00 & 421,00 & 464,00 & 505,00 & 510,00 & 650,00 \\
\hline 12 & ELSA & 230,00 & 227,00 & 333,00 & 493,00 & 595,00 & 515,00 & 535,00 \\
\hline 13 & EMTK & $9.500,00$ & $9.500,00$ & $9.450,00$ & $9.000,00$ & $9.225,00$ & $9.800,00$ & $9.700,00$ \\
\hline 14 & ERAA & 525,00 & 497,00 & 690,00 & 735,00 & 645,00 & 585,00 & 800,00 \\
\hline 15 & IBST & $2.900,00$ & $2.245,00$ & $1.900,00$ & $2.175,00$ & $1.965,00$ & $3.000,00$ & $2.600,00$ \\
\hline 16 & ICBP & $14.450,00$ & $15.750,00$ & $15.200,00$ & $15.275,00$ & $16.200,00$ & $17.225,00$ & $8.600,00$ \\
\hline 17 & IGAR & 250,00 & 229,00 & 250,00 & 275,00 & 270,00 & 675,00 & 725,00 \\
\hline 18 & KP & $3.495,00$ & $3.675,00$ & $3.725,00$ & $3.675,00$ & $3.770,00$ & $3.800,00$ & $3.800,00$ \\
\hline 19 & $\mathrm{INCO}$ & $1.445,00$ & $1.535,00$ & $1.750,00$ & $1.860,00$ & $1.655,00$ & $1.820,00$ & $2.560,00$ \\
\hline 20 & INTP & $19.700,00$ & $20.025,00$ & $19.725,00$ & $19.725,00$ & $16.650,00$ & $16.875,00$ & $17.075,00$ \\
\hline 21 & KAEF & $1.050,00$ & $1.075,00$ & $1.270,00$ & $1.205,00$ & $1.190,00$ & $1.155,00$ & $1.245,00$ \\
\hline 22 & LINK & $3.290,00$ & $3.630,00$ & $4.105,00$ & $4.215,00$ & $4.210,00$ & $4.060,00$ & $4.370,00$ \\
\hline 23 & LPFF & $16.000,00$ & $18.475,00$ & $18.350,00$ & $19.000,00$ & $18.975,00$ & $20.000,00$ & $19.925,00$ \\
\hline 24 & MAIN & $1.330,00$ & $1.320,00$ & $1.285,00$ & $1.370,00$ & $1.480,00$ & $1.625,00$ & $1.750,00$ \\
\hline
\end{tabular}




\begin{tabular}{|c|c|c|c|c|c|c|c|c|}
\hline 25 & NRCA & 585,00 & 640,00 & 625,00 & 610,00 & 665,00 & 610,00 & 605,00 \\
\hline
\end{tabular}

Sumber: $\underline{w w w . i d x . c o . i d}$

Analisis portofolio optimal dilakukan dengan mendasarkan perhitungan pada model Markowitz, dimana langkah-langkah yang harus ditempuh antara lain:

Pertama, menghitung return saham dari masing-masing sampel saham perusahaan sektor perbankan yang dinyatakan dalam satuan persen menggunakan rumus (Hartono, 2010:207):

Dimana:

$$
\text { Return }=\frac{P_{t}-P_{t-1}+D_{i}}{P_{t}}
$$

$\mathrm{P}_{\mathrm{t}} \quad=$ harga saham pada periode ke- $\mathrm{t}$

$\mathrm{P}_{\mathrm{t}-1} \quad=$ harga saham pada periode $\mathrm{t}-1$

$\mathrm{D}_{\mathrm{i}} \quad=$ dividen yang dibagikan

Kedua, menghitung expected return masing-masing sampel dengan rumus (Husnan, 2009:50):

Dimana:

$$
E\left(R_{i}\right)=\frac{\sum_{i=1}^{N} R_{i j}}{N}
$$

$\mathrm{E}\left(\mathrm{R}_{\mathrm{i}}\right) \quad=$ rata-rata expected return saham perusahaan ke- $\mathrm{i}$

$\mathrm{R}_{\mathrm{ij}} \quad=$ tingkat keuntungan pada investasi $\mathrm{i}$

$\mathrm{N} \quad=$ banyaknya peristiwa yang mungkin terjadi

2010:55):

Ketiga, menghitung varian masing-masing saham dengan rumus (Tandelilin,

dan

$$
2=[-()]^{2} \mathrm{pr}
$$

Dimana:

$$
\sigma=\left(\sigma^{2}\right)^{1 / 2}
$$

$\sigma^{2} \quad$ : Varians return

$\sigma \quad:$ Standar deviasi

$\mathrm{E}(\mathrm{R}) \quad$ : Return yang diharapkan dari suatu sekuritas

$\mathrm{R}_{\mathrm{i}} \quad$ : Return ke-i yang mungkin terjadi

$\mathrm{pr}_{\mathrm{i}} \quad$ : Probabilitas kejadian return ke- $i$

Keempat, mencari nilai kovarian antara dua buah saham dalam portofolio dengan rumus (Hartono, 2014:320):

Dimana:

$$
\sigma(R i, R j)=\sum=1 \frac{[(R,-E(R) .(R,-E(R \quad))]}{n}
$$

$\sigma_{\mathrm{Ri}, \mathrm{Rj}} \quad$ : Kovarian return antara saham i dan saham $\mathrm{j}$

$\mathrm{Ri}, \mathrm{t} \quad$ : Return saham i pada periode $\mathrm{t}$

$\mathrm{Rj}, \mathrm{t} \quad$ : Return saham $\mathrm{j}$ pada periode $\mathrm{t}$

$\mathrm{E}(\mathrm{Ri}) \quad$ : Expected return saham i

$\mathrm{E}(\mathrm{Rj}) \quad$ : Expected return saham $\mathrm{j}$

$\mathrm{n} \quad$ : Jumlah periode pengamatan(n) untuk sampel besar/paling sedikit 30 observasi dan (n-1) untuk sampel kecil.

Kelima, menghitung expected return portofolio yang telah terbentuk dengan rumus (Tandelilin, 2001:64): 
Dimana:

$$
\mathrm{E}\left(\mathrm{R}_{\mathrm{p}}\right)=\sum_{i=1}^{n}\left(\mathrm{~W}_{\mathrm{i} .} \mathrm{E}\left(\mathrm{R}_{\mathrm{i}}\right)\right.
$$

$\mathrm{E}\left(\mathrm{R}_{\mathrm{p}}\right)$ : Return portofolio yang diharapkan

$\mathrm{W}_{\mathrm{i}} \quad$ :Alokasi dana pada masing- masing saham

$\mathrm{E}\left(\mathrm{R}_{\mathrm{i}}\right) \quad$ : Return yang diharapkan dari saham

$\mathrm{n} \quad$ : Jumlah saham yang ada dalam portofolio

Keenam, varian portofolio dihitung menggunakan formula (Tandelilin, 2001:65):

$$
\sigma_{\mathrm{p}}=\left[W_{A}^{2} \sigma_{A}^{2}+W_{B}^{2} \sigma_{B}^{2}+2\left(W_{A}\right)\left(W_{B}\right)\left(\rho_{A B}\right) \cdot \sigma_{A} \sigma_{B}\right]
$$

Dimana :

$\sigma_{\mathrm{p}} \quad$ : standar deviasi portofolio

$W_{A} \quad$ : bobot portofolio pada aset A

$\rho_{A, B} \quad$ : koefisien korelasi aset A dan B

Ketujuh, menghitung proporsi investasi (Wi) dengan meminimumkan fungsi tujuan. Parameter kunci yang dipakai adalah Wi dengan batasn $\sum_{i=1}^{n} W_{i}=1, W_{i} \geq 0$ untuk $\mathrm{I}=1,2, \ldots, \mathrm{n}$, dan $\sum_{i=1}^{n} W_{i}, R_{i}=R_{p}$.

Kedelapan, menghitung expected return portofolio optimal dengan rumus yang sama pada langkah kelima.

Kesembilan, menentukan varian portofolio optimal dengan menggunakan rumus yang sama dengan langkah ketujuh dengan tambahan penggunanaan proporsi akhir bobot yang telah dihitung sebelumnya.

Apabila semua langkah-langkah telah dilakukan dengan benar, maka akan diperoleh portofolio optimal yang terdiri dari saham-saham potensial. Portofolio optimal akan terlihat dari hasil yang ditunjukkan oleh perhitungan proporsi investasi pada masingmasing saham. Jumlah saham pada portofolio optimal dapat berbeda dengan jumlah saham pada portofolio efisien.

\section{HASIL PENELITIAN DAN PEMBAHASAN}

Expected Return Saham

Perhitungan expected return memiliki andil yang cukup besar dalam menentukan saham-saham mana yang dipandang layak mendapat alokasi dana. Adapun expected return saham pada masing - masing perusahaan sampel penelitian dapat dilihat pada Tabel 2 berikut :

Tabel 2 Total Return Saham dan Expected Return (\%)

\begin{tabular}{|l|l|l|r|r|l|r|r|}
\hline No & $\begin{array}{l}\text { Kode } \\
\text { Saham }\end{array}$ & $\begin{array}{l}\text { Total } \\
\text { Return } \\
\text { Saham }\end{array}$ & $\begin{array}{l}\text { Expected } \\
\text { Return } \\
\text { E(Ri) }\end{array}$ & No & $\begin{array}{l}\text { Kode } \\
\text { Saham }\end{array}$ & $\begin{array}{l}\text { Total } \\
\text { Return } \\
\text { Saham }\end{array}$ & \multicolumn{1}{l|}{$\begin{array}{l}\text { Expected } \\
\text { Return } \\
\text { E(Ri) }\end{array}$} \\
\hline 1 & ACES & 21.58 & 3.60 & 14 & ERAA & 55.23 & 9.20 \\
\hline 2 & ARNA & 20.28 & 3.38 & 15 & IBST & 6.20 & 1.03 \\
\hline 3 & ASSA & 58.42 & 9.74 & 16 & ICBP & -31.69 & -5.28 \\
\hline 4 & BISI & 35.94 & 5.99 & 17 & IGAR & 166.36 & 27.73 \\
\hline 5 & BUVA & 10.78 & 1.80 & 18 & IIKP & 8.55 & 1.42 \\
\hline 6 & CASS & -3.47 & -0.58 & 19 & INCO & 66.13 & 11.02 \\
\hline 7 & CEKA & 87.46 & 14.58 & 20 & INTP & -12.90 & -2.15 \\
\hline 8 & CMNP & -22.81 & -3.80 & 21 & KAEF & 19.01 & 3.17 \\
\hline
\end{tabular}




\begin{tabular}{|l|l|r|r|l|l|r|r|}
9 & CSAP & 5.26 & 0.88 & 22 & LINK & 30.05 & 5.01 \\
\hline 10 & ECII & -19.37 & -3.23 & 23 & LPFF & 23.23 & 3.87 \\
\hline 11 & EKAD & 52.94 & 8.82 & 24 & MAIN & 28.73 & 4.79 \\
\hline 12 & ELSA & 104.57 & 17.43 & 25 & NRCA & 4.58 & 0.76 \\
\hline 13 & EMTK & 2.42 & 0.40 & \multicolumn{3}{|l}{} \\
\cline { 1 - 3 } & &
\end{tabular}

Sumber: Data diolah

Perhitungannya memperlihatkan bahwa saham dengan nilai expected return tertinggi dimiliki oleh saham Champion Pacific Indonesia Tbk (IGAR) sebesar 27.73 persen dan saham dengan nilai expected return terendah dimiliki oleh Indofood CBP Sukses Makmur Tbk (ICBC) sebesar -5.28 persen. Hasil ini menunjukkan bahwa saham IGAR diperkirakan mampu memberikan keuntungan yang diharapkan terbesar diantara dua puluh lima saham lainnya.

Varian Saham pada Expected Return Positif dan Tertinggi

Varian saham adalah penyimpangan yang mungkin terjadi antara tingkat pengembalian saham dengan rata-rata pengembalian saham selama periode penelitian. Pemilihan standar deviasi saham dapat dihitung dalam masing - masing perusahaan dengan memiliki expected return positif dan tertinggi, standar deviasi tersebut dapat dilihat pada Tabel 3 berikut:

\section{Tabel 3 Varian Saham pada Expected Return Positif dan Tertinggi}

\begin{tabular}{|l|l|l|l|l|l|}
\hline No & $\begin{array}{l}\text { Kode } \\
\text { Saham }\end{array}$ & $\begin{array}{l}\text { Varian } \\
\text { Saham }\end{array}$ & No & $\begin{array}{l}\text { Kode } \\
\text { Saham }\end{array}$ & $\begin{array}{l}\text { Varian } \\
\text { Saham }\end{array}$ \\
\hline 1 & ASSA & 18.443 & 4 & ERAA & 23.056 \\
\hline 2 & CEKA & 22.285 & 5 & IGAR & 60.333 \\
\hline 3 & ELSA & 25.661 & 6 & INCO & 16.851 \\
\hline
\end{tabular}

Sumber: Data diolah

Sesuai dengan perhitungan varian, saham yang memiliki nilai varian tertinggi ialah saham Champion Pacific Indonesia Tbk (IGAR) dengan nilai varian sebesar 60.33 persen dan varian terendah dimiliki oleh Vale Indonesia Tbk (INCO) sebesar 16.85 persen.

\section{Kovarian Antar Saham}

Nilai kovarian yang positif berarti penggabungan dua buah saham tersebut dalam portofolio memiliki kecenderungan bergerak ke arah yang sama. Sedangkan nilai kovarian yang bernilai negatif menandakan bahwa dua saham tersebut bergerak secara berlawanan, dalam artian apabila salah satu saham mengalami kenaikan pada return maka saham satunya akan menurun. Nilai kovarian antar saham dapat dilihat pada Tabel 4 berikut: 
Tabel 4 Kovarian antar Saham

\begin{tabular}{|l|l|c|c|c|c|c|c|}
\hline \multirow{2}{*}{ No } & \multirow{2}{*}{$\begin{array}{l}\text { Kode } \\
\text { Saham }\end{array}$} & \multicolumn{6}{|c|}{ Kovarian Antar Saham } \\
\cline { 3 - 8 } & ASSA & CEKA & ELSA & ERAA & IGAR & INCO \\
\hline 1 & ASSA & 0.02834 & 0.01230 & -0.00149 & 0.02862 & -0.02562 & 0.02277 \\
\hline 2 & CEKA & 0.01230 & 0.04139 & 0.01136 & 0.00502 & -0.06378 & -0.00379 \\
\hline 3 & ELSA & -0.00149 & 0.01136 & 0.05487 & 0.01976 & -0.06676 & -0.00681 \\
\hline 4 & ERAA & 0.02862 & 0.00502 & 0.01976 & -0.00333 & -0.03610 & 0.02466 \\
\hline 5 & IGAR & -0.02562 & -0.06378 & -0.06676 & -0.03610 & 0.30334 & 0.00204 \\
\hline 6 & INCO & 0.02277 & -0.00379 & -0.00681 & 0.02466 & 0.00204 & 0.02366 \\
\hline
\end{tabular}

Sumber: Data diolah.

Expected Return dan Risiko Portofolio dengan Proporsi yang Sama (dalam \%)

Penentuan proporsi dana yang sama menggunakan asumsi bahwa seluruh saham mendapatkan proporsi dana yang sama dengan menghitung expected return dan risiko portofolio. Proporsi dana pada portofolio mengasumsikan bahwa seluruh dana dibagi secara proporsional untuk masing - masing saham, sehingga setiap saham mendapatkan proporsi dana sebesar 16.67 persen. Hasil dari expected return dan risiko portofolio dengan proporsi yang sama dapat dilihat pada Tabel 5 berikut:

Tabel 5 Expected Return dan Risiko Portofolio dengan Proporsi yang Sama (dalam \%)

\begin{tabular}{|l|l|l|l|l|l|}
\hline No & $\begin{array}{l}\text { Kode } \\
\text { Saham } \\
\text { Dana }\end{array}$ & $\begin{array}{l}\text { Noporsi } \\
\text { No }\end{array}$ & $\begin{array}{l}\text { Kode } \\
\text { Saham }\end{array}$ & $\begin{array}{l}\text { Proporsi } \\
\text { Dana }\end{array}$ \\
\hline 1 & ASSA & 0.167 & 4 & ERAA & 0.167 \\
\hline 2 & CEKA & 0.167 & 5 & IGAR & 0.167 \\
\hline 3 & ELSA & 0.167 & 6 & INCO & 0.167 \\
\hline \multicolumn{5}{|l|}{ Expected Return } & 14.352 \\
\hline \multicolumn{5}{|l}{ Varian } \\
\hline
\end{tabular}

Sumber: Data diolah.

Dari hasil diatas menunjukan bahwa proporsi dana yang sama dalam ke-6 saham tersebut menghasilkan proporsi sebesar 0.167 dan memberikan expected return sebesar 14.352 persen dengan tingkat risiko sebesar 0.058 persen.

Pembentukan Portofolio yang Optimal

Portofolio optimal dibentuk dengan menggunakan aplikasi program Solver yang terdapat dalam Microsoft Excel. Perhitungan menggunakan program ini memperlihatkan proporsi dana akhir yang layak dialokasikan pada masing-masing saham. Hasil perhitungan disajikan dalam Tabel 6 berikut: 
Tabel 6 Expected Return dan Risiko Portofolio dengan Proporsi yang Optimal (dalam \%)

\begin{tabular}{|l|l|l|l|l|l|}
\hline No & $\begin{array}{l}\text { Kode } \\
\text { Saham }\end{array}$ & $\begin{array}{l}\text { Proporsi } \\
\text { Dana }\end{array}$ & No & $\begin{array}{l}\text { Kode } \\
\text { Saham }\end{array}$ & $\begin{array}{l}\text { Proporsi } \\
\text { Dana }\end{array}$ \\
\hline 1 & ASSA & 0.05 & 4 & ERAA & 0.01 \\
\hline 2 & CEKA & 0.08 & 5 & IGAR & 0.25 \\
\hline 3 & ELSA & 0.03 & 6 & INCO & 0.58 \\
\hline \multicolumn{2}{|l|}{ Expected Return } & \multicolumn{2}{l}{15.592} \\
\hline \multicolumn{2}{|l}{0.108} \\
\hline
\end{tabular}

Sumber: Data diolah.

\section{SIMPULAN}

Analisis dan perhitungan yang dilakukan memperlihatkan bahwa portofolio optimal yang dibentuk menggunakan model Markowitz terdiri dari enam buah saham, yaitu saham Adi Sara Armada Tbk (ASSA), Wilmar Cahaya Indonesia Tbk (CEKA), Elnusa Tbk (ELSA), Erajaya Swasembada Tbk (ERAA), Champion Pacific Indonesia Tbk (IGAR), dan Vale Indonesia Tbk (INCO). Perhitungan model Markowitz memperlihatkan keseimbangan antara nilai return dengan tingkat risikonya. Dengan bantuan aplikasi program Solver diketahui proporsi investasi pada masing-masing saham agar diperoleh return yang maksimal dengan tingkat risiko tertentu.

Investasi pada portofolio optimal ini memberikan total expected return portofolio sebesar 15.592 persen dengan tingkat penyimpangan risiko/varians portofolio sebesar 0,108 persen. Jelas terlihat perbedaan antara investasi pada portofolio yang menggunakan proporsi dana sama untuk masing-masing sahamnya dengan investasi pada portofolio optimal. Investasi di portofolio optimal memberikan tingkat expected return yang lebih besar dibandingkan dengan portofolio proporsi dana sama dengan tingkat penyimpangan risiko tertentu.

\section{DAFTAR PUSTAKA}

Ahmad, Kamaruddin. 2004. Dasar-Dasar Manajemen. Jakarta:PT Rineka Cipta.

Bangun, Deddy H, Samuel P. D. Anantadjaja, Laura Lahindah. 2012. Portofolio Optimal Menurut Markowitz Model dan Single Index Model : Studi Kasus pada Indeks LQ45. Journal of Management Studies, 1(1): h: 70-93.

Becker, Franziska, Marc Guertler, Martin Hibbeln. 2010. Markowitz Versus Michaud: Portfolio Optimization Strategies Reconsidered. Working Paper Series, No. IF30V3/09.

Djokopranoto, Richardus dan Richardus Eko Indrajit, 2011, "Wealth Management untuk Penyelenggaraan Perguruan Tinggi”, Penerbit: ANDI Yogyakarta.

Hartono, Jogiyanto. 2010. Teori Portofolio dan Analisis Investasi. Edisi Ketujuh. Yogyakarta:BPFE.

Husnan, Suad. 2009. Dasar-dasar Teori Portofolio \& Analisis Sekuritas. Edisi Keempat. Yogyakarta:UPP STIM YKPN.

Jogiyanto, 1998, “Teori Portofolio dan Analisis Investasi”, Edisi Pertama, Yogyakarta: Penerbit BPFE. 
Koch, Edward T., Debra DeSalvo dan Joshua A. Kennon, 2008, “The Complete Ideal's Guides: Investing", Penerbit: Prenada Media jakarta.

Manurung, Jonni, Adler Haymans Manurung. 2009. Ekonomi Keuangan dan Kebijakan Moneter. Jakarta: Salemba Empat. 884

Reilly, Frank K dan Keith C. Brown, 2003, "Investment Analysis and Portofolio Management", Salemba Empat: Jakarta. Rose, Mario D. D., 2012, "High Yield Means High Risk", Edward Jones, 1-4, USA.

Suqaier, Faten Shukri, Hussein Ali Al Ziyud. 2011. The Effect of Diversification on Achieving Optimal Portfolio. European Journal of Economics Finance, and Administration Sciences, 32(2011).

Tandelilin, Eduardus. 2010. Portofolio dan Investasi. Teori dan Aplikasi. Edisi Pertama. Yogyakarta:Kanisius.

Ticoh, Janne Deivy. 2010. Optimalisasi Portofolio Proyek Dengan Menggunakan Kurva Efisien Markowitz. Ed Vokasi, Jurnal Pendidikan Teknologi dan Kejuruan, 1(1): h: $36-57$.

Weston, J. Fred, \& Thomas E. Copeland, 1997, “Manajemen Keuangan”, Jakarta: Binarupa Aksara.

www.idx.co.id

www.pefindo.com 